Europe's Journal of Psychology 2/2010, pp. 175-179 www.ejop.org

\title{
A New Species of Trouble: Explorations in Disaster, Trauma and Community
}

Kai Erikson

W. W. Norton \& Company, 1994

Reviewed by Korstanje Maximiliano

University of Moron Argentina

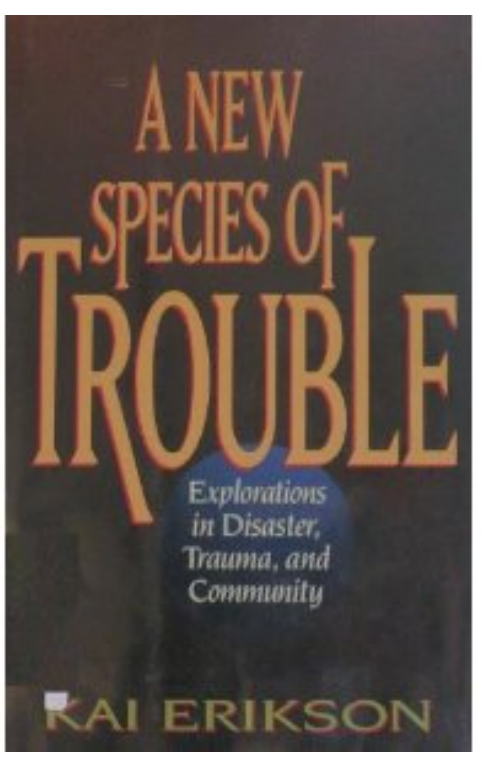

Current scholarship is based on the review of books no older than one or two years. No matter the contests or even the importance of the material, this kind of illfashioned dispositions impinge on the advance of Science; they don't allow for a broader re-discovery of other relevant projects which have been ignored for a considerable lapse of time. This is the case of the book authored by Kai Erikson, lecturer at Yale University. His valuable but contradictory work focuses on the exploration of trauma and social pathologies after-disasters. In a moment in which mankind is fraught with natural or made-man disasters, a project of this nature is fundamental in order for readers to understand the convergence of uncertainty with fear.

In the introductory section, Erikson narrates the case of Ojibwa, an Indian reservation located nearly to Grassy Narrows in Canada. Considering the high prevalence of murders induced by alcohol consumption, he argues a social disaster is gradually emerging in Grassy Narrow. Like a tornado or other natural catastrophe, social fragmentation and excessive alcohol consumption have blurring the bondage the self and the scaffolding of family. In the winter of 1970, Erikson witnessed as the Wabiggon's River has been gradually contaminated with mercury.

The fact was that people of Ojibwa ignored the fact that they were exposed to this poison for more than one decade. The effects of this were not observable on the short-run; clinical symptoms were associated to numbness of the mouth, problems in the brain, and clumsiness in walking, memory loss, impaired visions and finally depression. To be precise, "to make matters worse, the very fear that mercury to 
stimulate the real thing. I do not simply mean that apprehension about this or that symptom of mercury poisoning can help provoke its appearance, as is certainly true enough, but that dread itself has among its behavioral by-products the kind of disequilibrium, depression, memory loss and volatility that mercury is known for" (Erikson, 1994: 36). This moot point begs an interesting question, "was this poison responsible for the social pathologies linked to alcohol abuses Erikson saw at first glance"?

Undoubtedly, mercury caused havoc in the population of Grassy Narrows. However, mercury was not the only threat this community faced. White's colonization pushed natives to change their ancestral customs and form of tribe organization. This progressive disintegration of clans in combination with difficulties to track down and hunt animals made survival problematic for Grassy Narrows's natives. Typically, one might speculate disasters are linked to natural calamities such as floods, earthquakes or tsunamis; but of course humanitarian disasters are not under-explored by the specialized literature. Erikson with certain deep-insight brings into question to what extent our current understanding of a disaster is correct.

Anyway, things came from worse to worst. The Spaniard influenza outbreak that whipped the world from 1918 and 1919 killed a considerable part of the population in this reserve. Although a recovery process could be noticed and population climbed from 178 in 1917 to 242 in 1949, the epidemic resulted in a genuine shock for old-shamans who were hand-tied to heal infected people. Not only their reputation has been seriously jeopardized but also this represented a serious decline in religious beliefs. The White's man god embodied in Christianity was adopted by natives reinforcing the previous process of education accomplished by Canadian authorities from 1870 to 1890. "The Canadian Government had been charged by a treaty signed in 1873 to provide education to the Objibwa people, and it elected to meet that obligation by building residential schools, many of them run by missionaries at some distance from the reserves themselves. Whatever their intent, the effect of these schools was to separate children from their families for long stretches of time and to help strip them of their language, their native skills, their religion, and their very identify as Indians" (ibid. 45).

Let us remind readers that for Indian people in America the lands play an important role in the configuration of their own cosmology because they are seen as converging with the spirit of the ancestors. Lands bring security to dwellers because they are interrelated with the soul of rivers and mountains. Whenever persons change homes, they should be sure they will be welcomed. Otherwise, bad spirits impinge the families encouraging vicious acts, violence, and other type of 
calamities. The involuntarily migration - managed by the Canadian Government towards other reserves resulted in serious pathological problems for aboriginal tribes not only in Canada but also in the United States. Erikson realized that alienation and White hegemony seem to be key factors that lead these striking narrated stories of poverty, exclusion and self-humiliation in a difficult position, in a real humanitarian disaster.

The second chapter, similarly addresses the life of poor Haitians in Immokalee, a little town situated southward Everglades in Florida, US. This site is well recognized as a part of the country that attracts many illegal immigrants from the harvests, farmers or chronic migrants who roam from one site to another looking for opportunities of social upward. Erikson goes on to admit "In Inmokalee and in similar agricultural centers, more than 80 percent of the farmhands are citizens of other countries: the vast majority entered this country illegally, and only a few speak enough English to navigate successfully in this peculiar cultural waters" (ibid: 68). Bereft in conditions of misery and continuous necessities, these migrants are discriminated by residents, even compared with animals or with "excrements". In 22 March 1981, Miami Herald will refer to these newcomers as "Haitian Stampede". Despite the fact that Haiti was in past one of most prominent and important colonies of this hemisphere, now this country seems to be one of poorest with more than $80 \%$ of lands uncultivated, drained or infertile. Based on multiple marriages, Haitian's customs notably contrast with American ones. Very hard to define, their religion is a mixture of French Catholicism, Vodun of Africa and evangelical Protestantism. They often live overcrowded where a family formed by five or more members share a small-sized household of 176 feets and 16 foot-rooms.

To cut the long story short, Haitian peasants weekly send remittances to their relative in Haiti, many of them are sick or living in poverty. The disaster surfaced when Fred's (a company sending money from US soil to the island) was declared in bankruptcy because the embezzlement of funds of one of the owners. Erikson collected a number of striking chronicles from peasants who suffered the dead of a relative: father, mother or even child. The guilty owner (Fred Edenfield) was ultimately condemned by the courts of Florida only to thirty months of prison. Nonetheless, consequences for Haitians - for as little money as they were sent - were sorrowful. Psychologically speaking, affected people started to experience depression, insecurity, pain, sorrow, disorientation. Testimonies reported that children were hungry and without clothes at home. An event of this caliber affected the soul of the Haitian peasant deeper than anyone could imagine because it involved their relatives and children. The vulnerabilities of these deceived people resulted in a much broader state of insecurity and uncertainty. 
The case of East Swallow, in Colorado, described in third chapter, seems to be pretty different when compared with the previous ones, but the underlying problem remains, the fear of loosing what is of worth for the self. This town was alarmed in 1985 because a Gas company found a spill which threatened the population. This spill did not generate any damages on the short term, but further along effects over residents became increasingly dangerous. The intangibility of gas fumes in combination with the rise of continuous fears left residents of East Swallow in a full state of crisis. Erikson goes on to write in his report "the residents of East Swallow who where exposed to the effects of the gasoline spill complain - with considerable justice, one has to assume - that the value of their homes has declined precipitously as a result of recent events. In one sense, of course, that is a financial matter and outside the scope of this report: plaintiffs have invested large amount of capital into the dwelling they occupy, and they are understandably concerned about the safety of those investments. For many, maybe most of them, it is not just a matter of loosing a valuable possession; it is a matter of placing life's saving at risk" (ibid: 116). The two factors that most concerned workers were:

1. A broader exacerbated feeling of uncertainty about the health of family and relatives as well as the safety of their homes. These aspects represented one of main reasons for psychological distress in the population. On the one hand, they dreaded to leave their own households because things could worsen during their absence this means an explosion or a disaster of similar caliber - but for on the other hand, they were aware of the serious implication of not to leaving the affected zone: a gradual and inevitable intoxication with gas.

2. The second motive of distress was associated with the possibility of loosing the place they invested so much money and effort in. This phenomenon seems to be well-described in the context of disasters. For example, in moments of crisis many evacuation procedures fail because the personnel come across residents who are reluctant to abandon their homes.

The symbolic power of "home" in the construction of our identity is unquestionable but in this case-study things seem to be a bit different. Certainly, spills of gas can turn into a more frightful hazard that affects a wide range of social activities and of course workers were in part responsible for those damages; sadness, desperation and panic were some of the feelings Erikson noticed during his interviews. One of the relevant aspects that terrified the whole population in this zone was the unpredictability of the next disaster. Metaphorically speaking, trapped between the devil and the blue sea workers were in a terrifying situation. In addition, this terrible situation implicitly triggers new relations of support among neighbors. Affected 
persons looked in their community for the strength enough they have not the chance to locate in their home. Erikson assumes that whereas home emotionally represents the place where family lies, neighborhood plays a secondary role in the socialization process. Since home did not warrant any kind of ontological security lay-people deposited their trust in the neighborhood as a second option. It is important not to loose sight of the following excerpt that synthesizes the previous argument, "the People of East Swallow, then, must face life with not only the layers of emotional insulation represented by home and neighborhood in disrepair but the next outer layer represented by the wider community in disarray as well. To induce or encourage that sense of distrust and suspicion is a terrible thing for one human being to do to another" (ibid: 133).

Once transcribed in the present review, the most representative parts and narrations can make us speculate that this book juxtaposes a broader micro-sociological view of interviewed persons with structural theories in the research of disaster effects. Exploring the trauma with more than scientific objectivity, Erikson's account emphasizes the relationship of the agent with his/her environment (reminding of the classical contributions of $\mathrm{E}$. Durkheim regarding the role played by social relations in the suicide). A New Species of Trouble deserves to be re-discovered in light of contemporary perspectives; a work that not only triggers the discussion about humanitarian disasters but also captivates the human suffering as something else than a spectacle; in summary, a valuable project highly recommendable for anthropologists, sociologists, psychologists concerned with disaster-related issues. Nonetheless, one of the aspects that tarnish this brilliant work is related to Erikson's propensity not to conduct his own the field-work. Rather, tasks were delegated to assistant researchers. As a psychologist of cabinet, Erikson was limiting himself only to hear and analyze the data-set (as he overtly admitted in the book) others collected for him. From our point of view, personal contact and ethnographical reflexivity among researchers and informants are crucial for the commitment of observers with the topic of the research. The findings of this investigation would have been enriched if Erikson would have taken a proactive role in data collection. In the end though, this review is primarily intended to call for a're-discovery' of Kai Erikson's contribution to the study of psychological aftermaths of catastrophic events. 